\title{
DETENCIÓN DE MENORES EXTRANJEROS NO ACOMPAÑADOS EN EUROPA: LA NECESIDAD DE GARANTIZAR EFECTIVAMENTE LOS DERECHOS YA RECONOCIDOS
}

Juan Manuel López Ulla*

\begin{abstract}
El Consejo de Europa y la Unión Europea, en varios documentos aprobados entre 2010 y 2012, reconocen abiertamente que en Europa no se han adoptado las medidas suficientes para garantizar de manera efectiva los derechos reconocidos en la Convención de Naciones Unidas sobre los Derechos del Niño (1989) en relación con los menores extranjeros no acompañados. Por lo que se refiere a las condiciones en las que pueden ser detenidos, urge implementar un procedimiento común capaz de salvaguardar la tutela administrativa y jurisdiccional de estos menores.
\end{abstract}

Palabras clave: menores extranjeros no acompañados en Europa, detención, tratos inhumanos o degradantes, interés superior del menor, Tribunal Europeo de Derechos Humanos.

\section{Justificación y delimitación del objeto de estudio}

El Consejo Europeo que en 1999 se celebró en la ciudad finlandesa de Tampere, ya dejó patente la necesidad de una política común en materia de extranjería ${ }^{1}$. Desde entonces, los avances han sido importantes pero no suficientes. A pesar de la crisis económica, Europa sigue siendo un destino atractivo para miles de personas que cada año llegan o intentan llegar con la esperanza de un futuro mejor.

\footnotetext{
Facultad de Derecho de Jerez, Universidad de Cádiz. Jerez/España.

1 El Consejo Europeo de Tampere, reunido los días 15 y 16 de octubre de 1999 con carácter especial para tratar la creación del Espacio de Libertad, Seguridad y Justicia, definió la Política Común de Inmigración a partir de lo propuesto por el Plan de Acción de Viena, quedando configurada por tres ejes aglutinantes: codesarrollo (asociación con los países de origen), gestión de los flujos migratorios y trato justo y derechos comparables para los residentes legales.
} 
No se trata de ningún fenómeno coyuntural, advierten los especialistas en migraciones. En el contexto de la globalización, caracterizado por "la creciente interdependencia económica de los países de todo el mundo a través de un comercio internacional de bienes y servicios de un volumen y una variedad cada vez mayores, de flujos de capitales internacionales de un volumen y una variedad también crecientes y de una difusión de la tecnología más rápida y generalizada" (Fondo Monetario Internacional), el movimiento transnacional de seres humanos a lo largo y ancho del planeta será una realidad que influirá de manera decisiva en la conformación de las sociedades del siglo $\mathrm{XXI}^{2}$. Para el jurista, encauzar este complejísimo fenómeno para ordenarlo de la mejor manera representa todo un reto, un desafío que por sus dimensiones no se puede abordar de manera aislada. A pesar de las competencias soberanas de los Estado en materia de inmigración, la necesidad de homogeneizar procedimientos es del todo evidente.

En puridad no hablamos de algo nuevo. Los flujos migratorios han sido más intensos en unas épocas que en otras, pero nunca han dejado de existir. Geógrafos, sociólogos, economistas, politólogos, antropólogos, teólogos, por citar tan sólo algunas áreas del conocimiento, se han preocupado por las causas que animan estos movimientos y por los efectos que generan. También los juristas lo han hecho, si bien hemos de reconocer que en España, con anterioridad a 1998, eran pocos los trabajos publicados sobre la materia. En la medida en que la inmigración era prácticamente inexistente, la atención de los estudiosos se concentraba en otros puertos.

Como botón de muestra señalaremos que la Constitución española de 1978 no contempla la inmigración sino como título competencial que en exclusiva se reserva al Estado (art. 149.1.2). O que el Estatuto de Autonomía de Andalucía de 1981, Comunidad Autónoma a la que pertenece quien redacta estas líneas, en ninguno de sus preceptos se refería a la inmigración,

2 Informe de la Comisión al Consejo y al Parlamento Europeo. Informe intermedio de la aplicación del Plan de acción sobre los menores no acompañados, Bruselas, 28 de septiembre de 2012, COM (2012) 554 final. Concepto de menor no acompañado: "el nacional de un tercer país o el apátrida menor de 18 años que llegue al territorio de los Estados miembros sin ir acompañado de un adulto responsable de él, ya sea legalmente o con arreglo a la costumbre, mientras tal adulto responsable no se haya hecho cargo efectivamente del menor, o cualquier menor al que se deje solo tras su entrada en el territorio de los Estados miembros" (art. 2.f de la Directiva 2003/86/CE del Consejo, de 22 de septiembre de 2003, sobre el derecho a la reagrupación familiar; en el mismo sentido, el art. 2 h de la Directiva 2003/9/CE del Consejo de 27 de enero de 2003 por la que se aprueban normas mínimas para la acogida de los solicitantes de asilo en los Estados miembros; y art. 189 del Real Decreto 557/2011, de 20 de abril, por el que se aprueba el Reglamento de la Ley Orgánica 4/2000, sobre derechos y libertades de los extranjeros en España y su integración social, tras su reforma por Ley Orgánica 2/2009). 
mientras que cuatro de sus artículos se ocupaban de la emigración ${ }^{3}$. En 2007 este Estatuto fue sustituido por otro, y en este nuevo cambiaron las tornas, pues en él solo un artículo alude casi de pasada a la emigración (art. 245.3) mientras que la inmigración está presente en cuatro de ellos ${ }^{4}$.

Las buenas perspectivas económicas durante aquellos años convirtieron a España en un país atractivo para quines buscaban trabajo fuera de nuestras fronteras. Algunos datos demográficos nos dan una idea de esta transformación: entre 1975 y 1985 el número de extranjeros residentes en España aumentó en 76.682 personas; entre 1985 y 1995, en 257.802 personas; y entre 1995 y 2006, en 2.304 .530 personas $^{5}$. Este cambio de tendencia fue tan relevante que la misma Exposición de Motivos del Estatuto de Autonomía de Andalucía de 2007 lo advierte:

...Si durante el último cuarto de siglo se han producido transformaciones intensas en el mundo, estos cambios han sido particularmente acentuados en Andalucía, donde en ese periodo hemos pasado del subdesarrollo económico y cultural a un panorama similar al de las sociedades más avanzadas, como ejemplifica la inversión de nuestros flujos migratorios.

No ha sido, desde luego, una peculiaridad española. En los últimos años esta mayor presión migratoria también ha afectado a otros países europeos que hasta hace poco exportaban mano de obra. La repercusión generalizada de este aumento de los flujos migratorios ha fortalecido la idea de que es necesaria una respuesta común, de que hay que sentar las bases para articular una política inspirada en unos mismos principios.

En puridad la inmigración no es una materia que podamos identificar en función de uno o más elementos objetivos. La inmigración sólo es delimitable en función del elemento subjetivo. Es la condición de inmigrante, de trabajador extranjero, lo que condiciona el estatus jurídico de la persona en el territorio de acogida. A lo sumo, podemos admitir que se trata de una materia multidisciplinar, pero ésto y lo otro, viene a ser lo mismo. En la medida en que la inmigración afecta a todos los ámbitos de la vida, casi todas las ciencias o áreas de conocimiento se interesan por este fenómeno, como antes hemos señalado.

Puesto que no contamos con demasiado espacio, esta afirmación exige, sin mayor dilación, que concretemos a qué vamos a dedicar nuestras

3 Estatuto de Autonomía de Andalucía de 1981 (derogado), artículos 12.3, apartado 4, 23.3, 72.2 y 58.1, apartado g).

4 Véanse los artículos 10.3, apartado 17; 37.1, apartado 9; 62; y 245.

5 Datos que ofrece el Plan Estratégico de Inmigración y Ciudadanía 2007-2010, aprobado en Consejo de Ministros de fecha 17 de febrero de 2007. 
próximas líneas ${ }^{6}$. El ámbito territorial de nuestro estudio será Europa; el ámbito subjetivo, los menores extranjeros no acompañados; y el ámbito objetivo, la detención de éstos a causa de la irregularidad de su situación administrativa. Nos proponemos subrayar la necesidad de articular unas bases comunes, al menos en el ámbito de la Unión, sobre la manera de proceder cuando se detiene a uno de estos menores por la razón indicada.

Trataremos de subrayar que aún cuando los Estados tienen el derecho innegable a controlar sus fronteras, esta libertad no es absoluta, pues los compromisos asumidos en Derecho internacional se han de respetar ${ }^{7}$. Así, la detención de un inmigrante irregular, aún cuando se hubiere practicado de acuerdo con la legislación interna, podría terminar siendo calificada de trato inhumano o degradante si se realiza ignorando lo dispuesto en el Convenio Europeo de Derechos Humanos (CEDH) o en la Convención de Naciones Unidas sobre los Derechos del Niño (CDN). Esta posibilidad es aún mayor cuando la víctima pertenece a un colectivo cuya especial vulnerabilidad ha sido reconocida por la Unión Europea (UE) y por el Consejo de Europa ${ }^{8}$. Este será exactamente el tema que nos ocupe.

6 Para un mayor desarrollo del enfoque que la Unión Europea y el Consejo de Europa ha adoptado en relación con los menores extranjeros no acompañados, véanse nuestros tres siguientes trabajos, "La necesidad de un protocolo común en Europa sobre la detención de menores extranjeros no acompañados", Revista de Derecho Comunitario Europeo, n. 46, 2013, p. 1061-1090; "Alcance del artículo 3 del CEDH en relación con la detención de un menor extranjero no acompañado. La obligación positiva de no dejarle en desamparo", Teoría y Realidad Constitucional, n. 32, 2013, p. 481-497; "La detención de menores extranjeros no acompañados en el marco de la Unión Europea y del Consejo de Europa", Huri-Age. Consolider-Ingenio 2010, n. 11, 2013, p. 1-20.

Abdulaziz, Cabales y Balkandali c. el Reino Unido, Sentencia de 28 de mayo de 1985, parágrafo 67.

8 Entre los documentos de la UE y del Consejo de Europa que insisten una y otra vez en que los menores extranjeros no acompañados "representan un grupo particularmente vulnerable que requiere una mayor atención y respuestas específicas", véanse: la Resolución del Consejo de la Unión Europea, de 26 de junio de 1997, relativa a los menores no acompañados nacionales de terceros países (97) C221/03); la Comunicación de la Comisión de las Comunidades Europeas, Hacia una estrategia de la Unión Europea sobre los derechos de la infancia, de 4 de julio de 2006 [COM(2006) 367 Final], que parte de lo dispuesto en la Observación General núm. 6 de 2005 del Comité de Naciones Unidas sobre los derechos del niño, relativa al "trato de los menores no acompañados y separados de sus familias fuera de su país de origen" (39 periodo de sesiones, de 17 de mayo al 3 de junio de 2005); el apartado 6.1.7 del Programa de Estocolmo Una Europa abierta y segura que sirva y proteja al ciudadano [2010/c 115/01], aprobado por el Consejo Europeo de 10 y 11 de diciembre de 2009; la Directiva 2008/115/CE del Parlamento Europeo y del Consejo, de 16 de diciembre de 2008, relativa a normas y procedimientos comunes en los Estados miembros para el retorno de los nacionales de terceros países en situación irregular, y la Directiva 2003/9/CE, del Consejo de 27 de enero de 2003, por el que se aprueban normas mínimas para la acogida de los solicitantes de asilo en los Estados miembros también aluden a la vulnerabilidad de los menores extranjeros no acompañados. En el marco del Consejo de Europa, véanse la Recomendación CM/Rec(2007)9 del Comité de Ministros a los Estados miembros sobre proyectos de vida para menores migrantes no acompañados (aprobada por el Comité de Ministros el 12 de julio de 2007 en la reunión número 1002 de los Representantes de los Ministros); la Resolución 1810 (2011), de 15 de abril de 2011, de la Asamblea Parlamentaria del Consejo de Europa que lleva por título 


\section{La detención de menores no acompañados en Europa}

La detención de menores indocumentados y no acompañados en Europa es una práctica cada vez más habitual. Si entre los grupos más vulnerables de nuestra sociedad están los niños, la condición de inmigrante en situación de irregularidad multiplica para ellos los riesgos de pobreza y de exclusión social. La respuesta, sin embargo, por parte del Estado no se corresponde con esta realidad. Al contrario, el informe de 2008 de la Plataforma Internacional para la Cooperación en relación con los Menores no Acompañados (PICUM) denuncia las "políticas agresivas" de la que este colectivo es objeto 9 .

La vulnerabilidad de los menores ha sido reconocida en no pocas ocasiones por el Tribunal Europeo de Derechos Humanos (en adelante, $\mathrm{TEDH})$, advirtiendo que, de entre ellos, los inmigrantes irregulares no acompañados están particularmente expuestos a todo tipo de violencias. Esta mayor fragilidad, subraya el Tribunal, exige que las autoridades estatales extremen las medidas de protección, articulando aquellas que sean capaces de disuadir de manera efectiva cualquier atentando contra la integridad de los mismos $^{10}$.

Menores migrantes indocumentados en situación irregular: un motivo real de preocupación; la Recomendación 1985 (2011) del Comité de Migración, Refugiados y Migración de la Asamblea Parlamentaria del Consejo de Europa, con el título Menores migrantes indocumentados in situación irregular: un motivo real de preocupación. El TEDH en varias ocasiones ha recordado que los niños representan uno de los grupos más vulnerables de la sociedad, especialmente los menores inmigrantes ilegales no acompañados, y que debido a esta mayor fragilidad, la obligación de proporcionar una protección efectiva se hace particularmente necesaria. En relación con la necesidad de adoptar medidas efectivas que preserven sus derechos, véanse entre otras: K.A.B. C. España, de 10 de abril de 2012, parágrafo 95; Rahimi c. Grecia, de 5 de abril de 2011; M.S.S. c. Bélgica y Grecia, 21 de enero de 2011, parágrafo 251, Oršuš y otros c. Croacia, de 16 de marzo de 2010, parágrafo 147, Mubilanzila Mayeka y Kanili Mitunga c. Bélgica, de 12 Octubre de 2006, parágrafo 56; Okkali c. Turquía, 17 de octubre de 2006, parágrafo 70; A. c. Reino Unido, 19 de febrero de 2009, parágrafo 22; X e Y C. Holanda, 26 de marzo de 1985, parágrafos 21-27; Stubbings y otros c. Reino Unido, 22 de octubre de 1996, parágrafos 62-64; A. c. Reino Unido, 23 de septiembre de 1998, parágrafo 22.

9 Los niños indocumentados en Europa: Víctimas invisibles de las restricciones a la inmigración, PICUM (Platform for International Cooperation on Undocumented Migrants), 2008.

${ }^{10}$ En la Sentencia Rahimi c. Grecia, el TEDH en varios parágrafos hace referencia a que los niños representan uno de los grupos más vulnerables de la sociedad, y aún más los menores inmigrantes ilegales no acompañados; esta circunstancia es determinante para declarar la lesión del art. 3 $\mathrm{CEDH}$ cuando las autoridades no atienden la especial obligación que tienen de proteger a estas personas (parágrafos 86 y 87). Al respecto, la Sentencia Rahimi se remite a la Sentencia Mubilanzila Mayeka y Kaniki Mitunga c. Bélgica, parágrafo. 55, donde ya se subrayó que entre las circunstancias a valorar para determinar si se ha superado el umbral de sufrimiento que nos permite calificar una actuación de trato inhumano hay que considerar que los niños representan un grupo especialmente vulnerable de nuestra sociedad, especialmente los inmigrantes no acompañados en situación de irregularidad; esta circunstancia ha de tomarse especialmente en consideración cuando se presenta una denuncia relativa a las condiciones en las que se ha practicado la 
En relación con las condiciones en las que un menor extranjero puede quedar detenido, la Sentencia del TEDH que resuelve el caso Rahimi contra Grecia, de 5 de abril de 2011, resulta a nuestro juicio de una extraordinaria importancia. Se trata de la primera vez que la Corte ha considerado que dejar sin protección o en desamparo a un menor una vez que, dictada la orden de expulsión, éste abandona el centro de internamiento, representa una violación del art. 3 del CEDH. Ese precepto reza de la siguiente manera: "Nadie podrá ser sometido a tortura ni a penas o tratos inhumanos o Degradantes". Las circunstancias de este caso fueron las siguientes:

El recurrente es un menor afgano de 15 años de edad, de nombre Eiva Rahimi, que emigra después de que sus padres murieran en la guerra que asolaba su país. El mismo día que llega a la isla griega de Lesbos es arrestado y llevado al centro de internamiento Pagani, donde estuvo retenido durante dos días. Una vez que se le notifica la orden de abandonar Grecia en el plazo de 30 días, el menor fue puesto en libertad sin que tal decisión fuera acompañada de ninguna medida de protección o salvaguarda. Rahimi, en consecuencia, quedó en desamparo hasta que por sus propios medios consiguió abandonar la isla y llegar a Atenas, donde fue acogido por una asociación de ayuda a los inmigrantes. Fue entonces cuando presentó una

detención (parágrafos 55 y 56). En Okkali c. Turquía, de 17 de octubre de 2006, parágrafo 70: “los niños son particularmente vulnerables porque están expuestos en primera línea a diversos tipos de violencia, por lo que los gobiernos tienen la obligación de implementar las medidas de protección oportunas". En el mismo sentido, A. c. Reino Unido, de 19 de febrero de 2009, parágrafo 22, (que se remite mutatis mutandis, a la Sentencia X y Y c. Holanda, de 26 de marzo de 1985, parágrafos 21 a 27; a Stubbings y otros c. Reino Unido, de 22 de octubre de 1996, parágrafos 62 a 64; y también a los arts. 19 y 37 de la Convención de Naciones Unidas sobre los Derechos del Niños). En este sentido también, inter alia, A. c. Reino Unido, de 23 de septiembre de 1998, parágrafo 22. La Corte se ha pronunciado en varias ocasiones en relación con actos de violencia física contra los niños en el seno de la familia: entre otras, en las Sentencias A. c. Reino Unido, de 23 de septiembre de 1998, Z. y otros c. Reino Unido, de 10 de mayo 2001, y en E. y otros C. Reino Unido, de 26 noviembre 2001, donde el Tribunal recuerda que los niños son personas muy vulnerables, por lo que los gobiernos tienen la obligación positiva de tomar las medidas oportunas para disminuir, tanto como se pueda, las posibles situaciones de peligro real que pudieran ser previsibles, ya sea actuando sobre la ley, esto es, operando las modificaciones normativas que se adviertan necesarias, ya sea corrigiendo las posibles derivaciones fácticas del sistema. En Siliadin c. Francia, de 26 de julio de 2005, encontramos otro caso interesante: se trata de una residente togalesa menor de edad víctima de eso que hoy se conoce con el nombre esclavitud doméstica. Por vez primera la Corte asemejó el estado de servidumbre que había sufrido la recurrente con la esclavitud, declarando por ello la violación del artículo 4 de la Convención (que prohíbe la esclavitud y los trabajos forzados) y censurando que la legislación francesa no tipificara en el código penal conductas como éstas. Por lo que ahora más nos interesa, en el parágrafo 112 de esta Sentencia se subraya la obligación positiva que tienen los gobiernos de reprimir el crimen de manera efectiva, y particularmente la necesidad de prevenir de manera eficaz los atentados contra determinados colectivos de personas especialmente vulnerables, categoría a la que pertenecen los niños, cuya dignidad e integridad ha ser preservada en todo momento, de acuerdo con lo establecido en la Convención sobre lo derechos del niño (arts. 19 a 37). 
solicitud de asilo que a fecha de la Sentencia del Tribunal de Estrasburgo aún no había sido resuelta.

En su recurso contra la orden de expulsión, el recurrente alega que al ser detenido quedó ingresado en un centro de adultos, donde su condición de menor de edad en absoluto fue tomada en consideración. Tampoco lo fue una vez que quedó en libertad dictada la orden de expulsión, pues tal decisión no fue acompañada de medida asistencial alguna. También se queja el recurrente de que nunca se le informó de la razón de su detención ni de la posibilidad de recurrir tal decisión, así como de las lamentables condiciones de habitabilidad de ese centro de internamiento.

Al resolver el caso, el TEDH tomó en consideración varios informes de instituciones nacionales e internacionales y de organizaciones no gubernamentales que corroboraban la queja del recurrente sobre las condiciones del centro de detención de extranjeros de Pagani. Entre otros, destacan un par de informes del Comité Europeo para la Prevención de la Tortura y de las Penas o Tratos Inhumanos o Degradantes donde se califica de "abominables" e "insalubres más allá de cualquier descripción" las condiciones en las que los inmigrantes ilegales se encontraban detenidos, advirtiendo que las "deplorables condiciones" de este Centro representaban un peligro tanto para la salud de los internos como para la plantilla de trabajadores allí destinados. Por ello el Tribunal termina declarando que el demandante había sido objeto de un "tratamiento degradante e inhumano"11.

Esta Sentencia no es la primera en la que el TEDH declara que la detención de un menor en un centro de adultos representa una violación del artículo 3 del CEDH. Con anterioridad hay varias en relación con las condiciones en las que un menor no acompañado puede quedar detenido a causa de la irregularidad de su situación administrativa. La más importante de ellas fue la dictada en el caso Mubilanzila Mayeka y Kanili Mitunga c. Bélgica, de 12 de octubre de 2006, donde el TEDH subrayó que del artículo 3 del CEDH deriva la obligación "positiva" de los Estados de procurar los cuidados y la protección que estos menores necesiten como si de un nacional se tratara.

En primer lugar hay que subrayar el carácter excepcional que debe tener la orden de retener a un menor en un centro de internamiento. Esta decisión sólo ha de adoptarse cuando ninguna otra operación alternativa sea posible. Si éste fuera el caso, el menor no puede quedar detenido en las mismas condiciones que un adulto sino en un centro acondicionado

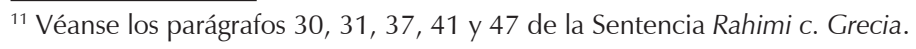


para menores y atendido por personas específicamente cualificadas para tratar con ellos, esto es, capaces de ofrecer el asesoramiento adecuado y la asistencia oportuna ${ }^{12}$.

Las circunstancias del caso Mubilanzila Mayeka y Kanili Mitunga c. Bélgica fueron especialmente particulares: se trataba de una menor congolesa de cinco años de edad, Ilamada Tabitha, que trataba de llegar hasta Canadá para reunirse con su madre. Durante dos meses, la niña estuvo detenida, en el mismo aeropuerto de Bruselas, en un centro de tránsito para adultos. Durante todo este tiempo, la menor estuvo separada de sus padres y no recibió ninguna medida de acompañamiento sicológico o de carácter educativo por parte de personal cualificado ${ }^{13}$. Finalmente, Tabitha fue expulsada.

En este caso, el TEDH llegó a la conclusión de que las medidas adoptadas por las autoridades belgas lejos habían estado de ser suficientes. La extrema vulnerabilidad de la menor por razón de su edad y de su situación (extranjera no acompañada en situación de irregularidad) fue determinante para que el Tribunal reprochara a las autoridades belgas "una falta de humanidad de tal calibre que alcanza la consideración de trato inhumano". El grado de sufrimiento que la niña tuvo que soportar a consecuencia de las condiciones de su detención superó el umbral necesario para considerar lesionado el art. 3 del $\mathrm{CEDH}^{14}$.

12 Mubilanzila Mayeka y Kaniki Mitunga c. Bélgica, op. cit., 2006, parágrafo 50: “The Court notes that the second applicant, who was only five years old, was held in the same conditions as adults. She was detained in a centre that had initially been designed for adults, even though she was unaccompanied by her parents and no one had been assigned to look after her. No measures were taken to ensure that she received proper counselling and educational assistance from qualified personnel especially mandated for that purpose. That situation lasted for two months. It is further noted that the respondent State have (sic) acknowledged that the place of detention was not adapted to her needs and that there were no adequate structures in place at the time". Véase también, Muskhaddzhiyeva y otros c. Bélgica, 19 de enero de 2010, parágrafo 56. Sobre esta Sentencia, SENOVILLA HERNÁNDEZ, Daniel. Comentario sobre la sentencia del Tribunal Europeo de Derechos Humanos de Estrasburgo de 12 de octubre de 2009: caso Mubilanzila Mayeka y Kanini Mitunga contra Bélgica. Revista de derecho migratorio y extranjería, n. 13, p. 187-198.

${ }^{13}$ En el caso D.G. c. Irlanda, de 16 de mayo de 2002, la Corte señala que no es aceptable que un menor se encuentre detenido en un Centro de internamiento durante varios meses sin previsión alguna sobre su derecho a la educación.

${ }^{14}$ Mubilanzila Mayeka y Kaniki Mitunga c. Bégica, op. cit., parágrafo 55: "The second applicant's position was characterized by her very young age, the fact that she was an illegal immigrant in a foreign land and the fact that she was unaccompanied by her family from whom she had become separated so that she was effectively left to her own devices. She was thus in an extremely vulnerable situation. In view of the absolute nature of the protection afforded by Article 3 of the Convention, it is important to bear in mind that this is the decisive factor and it takes precedence over considerations relating to the second applicant's status as an illegal immigrant. She therefore indisputably came within the class of highly vulnerable members of society to whom the Belgian State owed a duty to take adequate measures to provide care and protection as part of its positive obligations under 
Hemos de añadir que en el caso caso Mubilanzila Mayeka y Kanili Mitunga c. Bélgica, el Tribunal consideró lesionado el art. $3 \mathrm{CEDH}$ no sólo respecto de la niña sino también respecto de la madre. A causa de la detención de su hija, el TEDH entendió que las autoridades belgas habían actuado con una evidente falta de humanidad tamabién respecto de la madre. Sin embargo, esta transmisión familiar del dolor no tiene por qué producirse siempre entre padres e hijos, subraya la Corte, ni tiene por qué limitarse exclusivamente a los familiares que guarden una relación de consanguinidad de primer grado, sino que vendrá determinada por las circunstancias del caso. Entre otros, de la mayor o menor intensidad de los vínculos familiares, de la particularidad de las relaciones que mantengan unos y otros, y de la manera en la que las autoridades competentes gestionen en su conjunto la situación ${ }^{15}$. En este concreto supuesto, el TEDH entendió que el grado de sufrimiento que la madre tuvo que soportar por la detención de su hija estuvo incrementado por la actitud que frente a ella adoptaron las autoridades belgas, que se limitaron a proporcionarle un número de teléfono para que pudiera hablar con la pequeña. El TEDH entendió que esta actitud superó el umbral necesario para entender lesionado el artículo $3 \mathrm{CEDH}^{16}$.

Tras la Sentencia Mubilanzila Mayeka y Kanili Mitunga c. Bélgica, el Tribunal no ha dejado de recordar que un menor no debe ser detenido a menos que ninguna otra medida menos radical pueda ser adoptada, en cuyo caso el menor tendrá que ser internado en un centro apropiado y no en las mismas condiciones que los adultos ${ }^{17}$. En estas otras Sentencias posteriores, el Tribunal ha subrayado que la detención de un menor no

Article 3 of the Convention". Parágrafo 58: The Court considers that "the measures taken by the Belgian authorities - informing the first applicant of the position, giving her a telephone number where she could reach her daughter, appointing a lawyer to assist the second applicant and liaising with the Canadian authorities and the Belgian embassy in Kinshasa - were far from sufficient to fulfill the Belgian State's obligation to provide care for the second applicant. The Court is in no doubt that the second applicant's detention in the conditions described above caused her considerable distress".

${ }^{15}$ Exactamente, el Tribunal se expresa de la siguiente manera: "the proximity of the family tie - in that context, a certain weight will attach to the parent-child bond - the particular circumstances of the relationship and the way in which the authorities responded to the parent's enquiries". El tribunal reitera al efecto que "the essence of such a violation lies in the authorities' reactions and attitudes to the situation when it is brought to their attention"; $y$ al efecto se remite a la Sentencia Çakıcı c. Turquía, de 8 de julio de 1999, parágrafo 98, y Hamiyet Kaplan y otros c. Turquía, de 13 de septiembre de 2005, parágrafo 67.

${ }^{16}$ Mubilanzila Mayeka and Kaniki Mitunga c. Bélgica, op. cit., parágrafos 61 y 62.

17 SENOVILLA HERNÁNDEZ, op. cit. Sobre la condiciones de detención de menores no acompañados, KANICS, Jyothi; SENOVILLA HERNÁNDEZ, Daniel \& TOUZENIS, Kristina. Migrating alone. Unaccompanied and separated children's migration to Europe. Paris: Editions UNESCO Publishing, 2010. 
genera indefectiblemente un trato inhumano respecto de la madre sino que, como acabamos de apuntar, ello dependerá de las circunstancias del caso.

Un ejemplo de este otro supuesto en el que la madre no es considerada víctima de un trato inhumano (artículo $3 \mathrm{CEDH}$ ) a raíz de la detención de su hijo menor lo encontramos en la Sentencia Muskhadzhiyeva y otros C. Bélgica, de 19 de enero de 2010. En este caso, la madre quedó retenida junto a sus cuatro hijos menores, que en ningún momento quedaron separados de ella. El Tribunal concluyó que los primeros fueron objeto de un trato inhumano por las condiciones en las que estuvieron detenidos. Respecto de la madre, más allá de la frustración y el dolor que sin duda la situación le debió generar, el TEDH, a la luz de las concretas circunstancias del caso, concluye considerando que no se había traspasado el umbral de sufrimiento requerido para entender también respecto de ella conculcado el art. 3 $\mathrm{CEDH}$. En consecuencia, el daño infligido a los hijos no siempre supone que los padres también reúnan la condición de víctimas. Así será sólo cuando concurran determinadas circunstancias más allá del daño que normalmente provoca el hecho de que un hijo o un familiar cercano sea detenido ${ }^{18}$.

\section{El desamparo como trato inhumano}

Acabamos de ver que en relación con las condiciones de la detención de un menor extranjero no acompañado, la Sentencia Rahimi c. Grecia (2011) recuerda la doctrina que cinco años antes estableciera por vez primera la Sentencia Mubilanzila Mayeka y Kanili Mitunga c. Bélgica (2006). Sin embargo, la Sentencia Rahimi da un paso más que debe ser justamente valorado, y que pone de manifiesto la importancia de la labor interpretativa que el TEDH realiza del Convenio con el principal objetivo de garantizar efectivamente los derechos que en él se reconocen ${ }^{19}$.

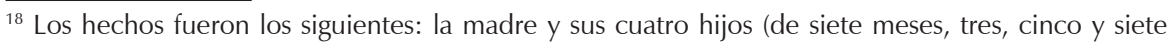
años de edad) fueron detenidos en la Oficina de Extranjeros cercana al aeropuerto de Bruselas a la espera de su deportación, una vez que la solicitud de asilo presentada fuera denegada. Para declarar la lesión del art. 3 CEDH respecto de los hijos, el Tribunal tomó en consideración varios informes independientes que habían concluido que ese Centro de detención no era apropiado para ingresar a niños. A mayor abundamiento, la organización Médicos Sin Fronteras había examinado a los niños, reconociendo en su Informe traumatismos síquicos y somáticos graves, sobre todo de uno de ellos. A la luz de estas circunstancias, el Tribunal concluyó que las condiciones en las que los niños habían estado en el centro de detención habían superado el umbral de gravedad exigido para entender conculcado el art. $3 \mathrm{CEDH}$ (Muskhadzhiyeva y otros c. Bélgica, 19 de enero de 2010, parágrafos 58 a 60, 63 y 66).

19 "The Convention is a living instrument which must be interpreted in the light of present-day conditions": entre otras, Tyrer c. Reino Unido, 25 de abril de 1978, parágrafo 31; Soering c. Reino Unido, 7 de Julio de 1989, parágrafo 102; Loizidou c. Turquía, 23 de marzo de 1995, parágrafo 71; Selmouni c. Francia, 28 de julio de 1999, parágrafo 101; Scozzari y Giunta c. Italia, de 13 de julio de 2000, parágrafo 138; Mubilanzila y Kaniki Mitunga c. Bélgica, de 12 de octubre de 
El CEDH ha de ser objeto de una lectura abierta, dinámica, progresiva. Tiene que ser concebido como un instrumento capaz de responder a las amenazas que cada vez de manera más sofisticada acechan sobre los derechos. Y esta función de adaptación, más allá de las modificaciones convencionales que de manera puntual se consideren convenientes, recae en buena medida sobre el TEDH.

Es muy habitual que un Tratado internacional comience señalando que por medio del mismo los Estados firmantes se comprometen a observar determinados compromisos. Sin embargo, la CEDH se expresa de una manera contundente que no deja lugar a dudas sobre el espíritu que la anima: los estados firmantes reconocen (no se comprometen a reconocer) a todas las personas bajo su jurisdicción los derechos libertades reconocidos en esta Carta. No estamos, pues, hablando de principios programáticos o de una mera declaración de intenciones sino de una realidad que hay que asegurar desde el primer momento para no incumplir el tratado. En la Sentencia Rahimi, consciente el Tribunal de que va a dar un paso más en la protección del derecho a no recibir tratos inhumanos o degradantes, así lo recuerda en varias ocasiones como si del hilo conductor de su discurso se tratara.

Son bastantes las resoluciones en las que el TEDH subraya que los derechos reconocidos en el $\mathrm{CEDH}$ no representa algo teórico sino que se trata de un documento con fuerza jurídica vinculante, por lo que los Estados miembros del Consejo de Europa han de adoptar las medidas pertinentes para efectivamente el texto se respete en lo concreto ${ }^{20}$. Al efecto, en relación con el artículo 3 del CEDH, no son pocas las ocasiones en las que el Tribunal ha recordado que este precepto, por una parte consagra una "prohibición absoluta y sin excepción de la tortura y de las penas que comporten un trato inhumano o degradante" 21 , lo que significa que bajo ninguna circunstancia

2006, parágrafo 48. Entre las más recientes, K.A.B. c. España, de 10 de abril de 2012, parágrafo 96, que al respecto recuerda lo ya señalado en la Sentencia Artico c. Italia, de 13 de mayo de 1980, parágrafo 33. Así, por ejemplo, ciertos actos que en el pasado fueron clasificados como tratamientos inhumanos y degradantes, podrían ser clasificados de manera diferente en el futuro (Selmouni c. Francia, 28 de julio de 1999, parágrafo 101); y también en Mubilanzila Mayeka and Kaniki Mitunga c. Bélgica, 12 de octubre de 2006, parágrafo 48.

${ }^{20}$ Véase, por ejemplo, Mubilanzila Mayeka y Kaniki Mitunga c. Bélgica, de 12 de octubre de 2006, parágrafo 54. En Okkali c. Turquía, de 18 de octubre de 2005, parágrafo 54, el Tribunal advierte que el recurso presentado "hace referencia a la obligación positive a la que hace referencia el art. 3 del CEDH de proteger la integridad física y psíquica de las personas (véase, mutatis mutandis, Öneryıldız c. Turquía, parágrafo 95)".

${ }^{21}$ En este sentido, Soering c. Reino Unido, de 7 de julio de 1989, parágrafo 88; Bati y otros c. Turquía, de 3 de junio de 2004, parágrafo 120. En Mubilanzila Mayeka y Kaniki Mitunga c. Bélgica, de 12 de octubre de 2006, parágrafo 55, la Corte recuerda "el carácter absoluto de la prohibición del art. 3 del Convenio". 
nadie puede ser sometido a medidas de esta naturaleza; pero que también de este precepto se deriva una obligación para los Estados: la de adoptar las medidas necesarias que garanticen la efectividad de este derecho. Para hacer notar esta la actitud vigilante, esta conducta activa que las autoridades nacionales han de adoptar, el Tribunal califica esta obligación de "positiva". Esto es, la prohibición del artículo $3 \mathrm{CEDH}$ no sólo compele a un no hacer sino que leído de acuerdo con el art. $1 \mathrm{CEDH}^{22}$, exige también que el Estado adopte las acciones necesarias para garantizar que esta prohibición se observa efectivamente ${ }^{23}$.

A la hora de evaluar si el artículo 3 del CEDH ha sido violado, el Tribunal a menudo recuerda que "el trato degradante ha de tener un mínimo nivel de gravedad ("ill-treatment must attain a minimun level of severity"), y que tal apreciación depende de las circunstancias que se presenten en cada caso concreto, esto es, de la naturaleza y del contexto del tratamiento, de la modalidad de ejecución, de su duración, de los efectos efectos psíquicos y sicológicos que hubiera podido causar, del sexo, de la edad, del estado de salud de la víctima ${ }^{24}$. Obviamente, la condición de menor extranjero no acompañado adquiere en esta evaluación una relevancia extraordinaria ${ }^{25}$, pero no absoluta. Como antes hemos comentado, la minoría de edad no es una circunstancia que indefectiblemente o de manera automática genere la consideración de que la persona pertenece al grupo de los más vulnerables. Para llegar a tal conclusión habremos de ponderar la mayor o menor edad

22 Artículo 1. "Obligación de respetar los derechos humanos.- Las Altas Partes Contratantes reconocen a toda persona bajo su jurisdicción los derechos y libertades definidos en el Titulo I del presente Convenio".

${ }^{23}$ Rahimi c. Grecia, de 5 de abril de 2011, parágrafo 62. Mubilanzila Mayeka y Kaniki Mitunga c. Bélgica, cit., parágrafo 53. Esta última resolución se remite a $Z$ y otros c. Reino Unido, de 10 de mayo de 2001, parágrafo 73; y a A. c. Reino Unido, de 23 de septiembre de 1998, parágrafo 22.

${ }^{24}$ Rahimi c. Grecia, cit., parágrafo 86: la apreciación del umbral del mínimo de gravedad de un tratamiento al objeto de considerarlo prohibido por el art. 3 de la Convención es relativo por principio. Dependerá al mismo tiempo de los hechos de la causa (Labita c. Italia [GC], no 26772/95, §120, CEDH 2000-IV), y notablemente de la naturaleza y el contexto del tratamiento, de su duración y de sus efectos psíquicos o mentales, así como, a veces, del sexo, de la edad y del estado de salud de la víctima (Price c. Reino Unido, n. 33394/96, § 24, CEDH 2001-VII; Mikadzé c. Rusia n. 52697/99, parágrafo 108, de 7 de junio de 2007). En el mismo sentido, Mubilanzila Mayeka y Kaniki Mitunga c. Bélgica, de 12 de octubre de 2006, parágrafo 48; Assenov y otros, c. Bulgaria, de 28 de octubre de 1998, parágrafo 94: "the assessment of this minimum is relative: it depends on all the circumstances of the case, such as the duration of the treatment, its physical and/ or mental effects and, in some cases, the sex, age and state of health of the victim". Véase también, M.S.S. c. Bélgica y Grecia, 21 de enero de 2011, parágrafos 219 y 220; y en el mismo sentido Raninen c. Finlandia, de 16 de diciembre de 1997, parágrafo 55.

25 Z y otros c. Reino Unido, de 10 de mayo de 2001, parágrafo 73; Osman c. Reino Unido, de 28 de octubre de 1998, parágrafo 116; A. c. Reino Unido, de 23 de septiembre de 1998. 
del menor, la salud, su madurez, su capacidad intelectual y emocional y demás circunstancias específicas del caso.

El art. 3 de la Convención exige al Estado asegurar que las detenciones se efectúen en condiciones compatibles con el respeto a la dignidad humana. Esto quiere decir que al practicar esta medida cautelar, se ha de procurar que la misma no genere un grado de sufrimiento superior al normal o inevitable en este tipo de actuaciones. A la hora de controlar que efectivamente así ha sido, de nuevo hemos de señalar que las circunstancias concretas del caso serán determinantes; y también la manera en que las autoridades nacionales gestionen cada detención ${ }^{26}$.

En la Sentencia Rahimi, tiene particular importancia la queja del recurrente en relación con la legalidad de su detención. Es cierto que la detención no es una medida irrazonable cuando se trata de asegurar la expulsión del inmigrante que no ha respetado las condiciones legalmente establecidas para entrar en un país. Pero en este caso, el Tribunal advierte que la legislación se aplicó de manera automática, sin tomar en consideración que se trataba de un menor no acompañado.

Tanto en la Sentencia Tabitha (2006) como la Sentencia Rahimi (2011), el Tribunal se apoya en los arts. 3.1 y 37 b) del CDN: cualquier medida administrativa en relación con un menor debe de tomar en consideración el principio del interés superior del menor ${ }^{27}$, señala el primero; y ningún menor puede quedar detenido a no ser que ninguna otra medida menos radical que la privación de libertad fuera posible, dice el segundo. O lo que es lo mismo, el ingreso en un centro de internamiento siempre ha de concebirse como una medida excepcional. La razón no es difícil de imaginar: la experiencia ha demostrado que esos ambientes marcan a menudo de manera irreversible el comienzo de una trayectoria personal delictiva ${ }^{28}$.

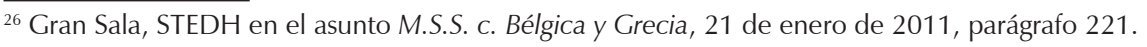

${ }^{27}$ Una definición de lo que puede considerarse trato degradante puede encontrarse en la Sentencia Raninen c. Finlandia, de 16 de diciembre de 1997, y también en la Sentencia Pretty c. Reino Unido; Tyrer c. Reino Unido, de 28 de abril 1978).Si bien el CEDH no contiene disposiciones específica en relación con el derecho a la asistencia sanitaria, el TEDH, en el caso Pretty vs. Reino Unido señaló que "el sufrimiento que deriva de enfermedades naturalmente contraídas, físicas o mentales, puede quedar cubierto por el artículo 3, si es o podría ser exacerbado por el trato, si este deriva de condiciones de detención, expulsión u otras medidas, para las que las autoridades puedan ser consideradas responsables" (Sentencia de 29 de abril 2002, parágrafo 52).

${ }^{28}$ Art. 3.1- "En todas las medidas concernientes a los niños que tomen las instituciones públicas o privadas de bienestar social, los tribunales, las autoridades administrativas o los órganos legislativos, una consideración primordial a que se atenderá será el interés superior del niño". Art. 37. "Los Estados parte velarán por que: (...) b) Ningún niño sea privado de su libertad ilegal o arbitrariamente. La detención, el encarcelamiento o la prisión de un niño se llevará a cabo de conformidad con la ley y se utilizará tan sólo como medida de último recurso y durante el período
} 
Fueron varias las circunstancias que el Tribunal apreció para concluir que la detención de Rahimi no se había realizado de acuerdo con los criterios establecidos en el CDN. Así, el Tribunal declara que si bien no puede considerarse excesivo el tiempo que el menor estuvo detenido (48 horas), las autoridades griegas ordenaron el ingreso del menor en el centro de internamiento sin tomar en consideración la posibilidad de adoptar otra medida menos radical, de acuerdo con el principio del interés superior del menor. El Tribunal utiliza este argumento, que como vemos está fundamentado en la Carta de Naciones Unidas sobre los derechos del niño, para declarar la violación tanto de los artículos $3^{29}$ y $5.1 \mathrm{CEDH}^{30}$. Este mismo argumento el Tribunal ya lo había empleado en Muskhadzhiyeva y otros C. Bélgica (2010), que anteriormente hemos citado: la minoría de edad del detenido debe determinar las decisiones a adoptar por las autoridades competentes. Las condiciones en las que un menor puede quedar detenido no pueden ser las mismas que las de un adulto ${ }^{31}$.

En el caso Rahimi c. Grecia, otras circunstancias que condujeron a estimar el recurso fue que el chico había sido registrado por las autoridades griegas como si encontrara acompañado por un familiar (un primo) cuando realmente no lo estaba; que la orden de detención y deportación se le comunicó en un idioma que no entendía, lo que le dejaba sin posibilidad alguna de defensa32; y que durante todo el proceso ni se le asignó tutor, ni recibió asesoramiento legal o de ningún tipo ${ }^{33}$. Por ello el Tribunal considera que también hubo una violación del art. 5.4 $\mathrm{CEDH}^{34}$.

más breve que proceda; (...)". Véase al respecto, Neuling y Shuruk c. Suiza, 6 de julio de 2010, parágrafo 135; Rahimi c. Grecia, 5 de abril de 2011, parágrafo 108.

29 Sentencia Rahimi c. Grecia, parágrafo 86.

${ }^{30}$ Sentencia Rahimi c. Grecia, cit., parágrafos 109 y 110.

${ }^{31}$ En este caso el Tribunal consideró legítima la detención de la madre pero no la de sus hijos. El Tribunal consideró que if the detention of a child seeking asylum, alone or accompanied by their parents, takes place in a center that is not specifically adapted to the reception of children, there could be a violation of article 5.1 of the Convention, even if they are confined for a short period of time (Muskhadzhiyeva y otros contra Bélgica, 19 de enero de 2010, parágrafo 74). Véase también el parágrafo 56 de esta Sentencia, que al efecto se remite al parágrafo 50 de la Sentencia Mubilanzila Mayeke y Kaniki Mitunga c. Bélgica.

32 Although he received a document written in Arabic, he didn't understand this language.

${ }^{33}$ In Rahimi v. Greece, 5th April 2011, paragraph 89, the Court states that United Nations High Commissioner for Refugees has already found that Greek district attorneys, who should be appointed as provisional guardians, in practice do not take part in the proceedings relatint to immigrant children. In paragraph 93, the Court recalls that in M.S.S. v. Belgium and Greece, 21 January 2011, paragraph 236, it has been denounced "the precariousness and vulnerability of asylum seekers in Greece" and the passivity of the Greek authorities to address this problem.

34 Rahimi v. Greece, $5^{\text {th }}$ April 2011, paragraph 120 and 121. 
Pero, más allá de las condiciones en las que el menor estuvo detenido (calificadas por el Tribunal de horribles y espantosas), lo verdaderamente novedoso del caso Rahimi c. Grecia es que se trata de la primera Sentencia en la que se declara la violación del artículo 3 del CEDH por dejar a un menor sin asistencia al salir del centro de internamiento, una vez dictada la orden de expulsión. El menor extranjero en situación irregular no puede quedar en desamparo. Debe de recibir la asistencia legal y social que el Estado de acogida contemple para los nacionales menores de edad. Nunca antes el TEDH había llegado a tal conclusión; nunca antes el Tribunal había advertido que la minoría de edad es una circunstancia de relevancia a tener en cuenta no sólo antes y durante la detención, como la Sentencia Tabitha había subrayado, sino también después, cuando sale del centro de internamiento ${ }^{35}$.

Para llegar a esta conclusión, el TEDH vuelve a apoyarse en los mismos preceptos del CDN, de 1989, que antes le habían llevado a declarar que el internamiento en un centro de adultos representaba una violación del $\mathrm{CEDH}$. Concretamente, en el art. 3 del CDN, que consagra el principio del interés superior del menor ${ }^{36}$, y en el art. 37 del $C D N$, que ordena que un menor no quede privado de libertad a no ser que ninguna otra medida fuera posible ${ }^{37}$. Que el Tribunal considere lesionado el art. 3 del CEDH utilizando como argumento fundamental, como ratio decidendi - no a mayor abundamiento (obiter dictum) - el no cumplimiento de las obligaciones establecidas en estos dos preceptos, pone de manifiesto la fuerza que en materia de derechos humanos han de tener los tratados internacionales ${ }^{38}$. El incumplimiento del

35 This attitude generated in the child a deep anguish and concern. The Court assumes the report of the NGO ARSIS saying that the child arrived to its hostel extremely thin and with other problems, such as distress and fear of darkness. See Rahimi v Greece, $5^{\text {th }}$ of April 2011, paragraphs 92, 94 and 95. The Court takes into consideration that Greek Ombudsman has reported that when children detained in Pagani centre are released, the authorities neither provide them with housing nor provide them any help. The Court also takes note of the report entitled "Let them survive: the systematic failure of the protection of unaccompanied migrant children in Greece" (Human Rights Watch, 2008). This report reflects the precarious situation in which these children are when they are released after a period of detention.

${ }^{36}$ Art. 3.1 of the CRC: "In all actions concerning children, whether undertaken by public or private social welfare institutions, courts of law, administrative authorities or legislative bodies, the best interests of the child shall be a primary consideration".

37 Art. 37 b) of the CRC: "No child shall be deprived of his or her liberty unlawfully or arbitrarily. The arrest, detention or imprisonment of a child shall be in conformity with the law and shall be used only as a measure of last resort and for the shortest appropriate period of time".

${ }^{38}$ Mubilanzila Mayeka y Kaniki Mitunga c. Bélgica, parágrafo 81, también advirtió que el no cumplimiento de las obligaciones contraídas internacionalmente puede conducir a una declaración de violación del artículo $3 \mathrm{CEDH}$ : “(...) the Contracting States are under a duty to maintain public order, in particular by exercising their right, as a matter of well-established international law, to control the entry and residence of aliens. In this connection, detention in centers used for aliens awaiting deportation will be acceptable only where it is intended to enable the States to combat 
Convenio de Naciones de Naciones Unidas sobre los Derechos del Niño deriva en una lesión del art. 3 del CEDH.

Aún cuando el carácter vinculante del CDN está fuera de toda duda, que el TEDH haya fundamentado una Sentencia estimatoria en la violación de este documento, consideramos que debe de ser destacado. Como también, que en el marco de la Unión Europea, el Plan de acción sobre los menores no acompañados (2010 - 2014) también haya subrayado que la realidad del elevado número de menores no acompañados en el territorio debe de abordarse desde el respeto al principio del interés superior del menor $^{39}$. La Comisión Europea advierte en este documento la necesidad de que los problemas en relación con los menores sean abordados a partir de un enfoque común que debiera partir del "respeto de los derechos del niño, tal como han sido reconocidos en la Carta de los Derechos Fundamentales de la UE y en la CDN, y especialmente en el principio del "interés superior del menor", que debe ser la consideración principal de toda acción emprendida por las autoridades en relación con los menores". Subraya la Comisión que "es fundamental asegurar que cualquier menor que necesite protección la reciba y que, independientemente de su estatuto de inmigrante, de su nacionalidad o de sus orígenes, todos los menores sean tratados, en principio y ante todo, como menores". Al efecto, la Comisión advierte la necesidad de "na mayor cooperación entre la UE y los países de origen y de tránsito de estos menores, y la necesidad de contar a este propósito con la colaboración de las organizaciones especializadas de la sociedad civil y de las organizaciones internacionales ${ }^{40}$.

En el marco del Consejo de Europa, la Resolución $1810(2011)^{41}$ de la Asamblea Parlamentaria del Consejo de Europa, reconoce que a pesar de que diversos órganos y organismos de Derecho internacional se han pronunciado en contra de la detención de los menores no acompañados, ésta es una

illegal immigration while at the same time complying with their international obligations, including those arising under the European Convention on Human Rights and the Convention on the Rights of the Child (...)". Con posterioridad a la Sentencia Rahimi, el Tribunal ha vuelto a recordar las obligaciones que derivan de la Convención de los Derechos del Niño: concretamente en Muskadzhiyeva y otros c. Bélgica, op. cit., el Tribunal recuerda que el artículo 22 de este Tratado obliga a los Estados a adoptar las medidas de protección oportunas cuando un menor, ya se encuentre solo o acompañado de sus padres, solicite asilo (parágrafo 62).

${ }^{39}$ Comunicación de la Comisión al Parlamento Europeo y al Consejo, de 6 de mayo de 2010, COM (2010) 213 final.

${ }^{40}$ Comunicación de la Comisión al Parlamento Europeo y al Consejo. Plan de Acción sobre los menores no acompañados (2010 - 2014) sec(2010)534.

${ }^{41}$ Resolución 1810 (2011), de 15 de abril de 2011, de la Asamblea Parlamentaria del Consejo de Europa que lleva por título Menores migrantes indocumentados en situación irregular: un motivo real de preocupación (Unaccompanied children in Europe: issues of arrival, stay and return). 
práctica común en muchos de los Estados miembros del Consejo de Europa. Los menores son con frecuencia detenidos junto con los adultos y sin que se les asesore jurídicamente o de algún otro modo. A este respecto, el noveno de los quince principios comunes que este documento relaciona invitando a los Estados parte a que los pongan en práctica vuelve a insistir en que la detención de menores no acompañados por razones relativas a la inmigración no debiera permitirse, salvo que ninguna otra medida menos radical fuera posible. En este último caso, el menor debiera quedar ingresado en un centro acondicionado para menores, nunca en los mismos centros o en las mismas condiciones que los adultos. En este sentido con anterioridad ya se había pronunciado la Resolución de la Asamblea 1707 (2010) de retención de solicitantes de asilo o de inmigrantes irregulares en Europa y el Plan de Acción de la UE (apartado 39 de este documento). Al efecto, la Recomendación 1985 (2011), también de la Asamblea Parlamentaria, propone la elaboración de algo parecido a un "documento base" o a una "guía de buenas prácticas" que pudiera ayudar a armonizar la legislación de todos los Estados parte en relación con las condiciones de la detención de los menores ${ }^{42}$. En concreto, en relación con España, el cuarto informe de la Comisión Europea contra el Racismo y la Intolerancia, adoptado el 7 de diciembre de 2010 y publicado el 8 de febrero de 2011, exhorta a las autoridades española para que se respete el derecho internacional y los derechos de los niños principalmente en relación con la obligación de asistir a los niños no acompañados sujetos a repatriación de un representante legal independiente, y de informarles de su derecho a solicitar asilo (apartados 169 a 175).

El progresivo aumento de la población inmigrante en Europa ha avivado la discusión sobre la vigencia efectiva de determinados Tratados y Convenios Internacionales: los derechos humanos han de estar convenientemente garantizados; el mero reconocimiento no es suficiente. Concretamente, en relación con las condiciones en las que un menor extranjero puede quedar detenido, así lo han denunciado el Consejo de Europa y la Unión Europea, en los documentos y en las resoluciones a las que hemos hecho referencia en este trabajo. Se precisa un procedimiento marco articulado a partir de los principios y derechos reconocidos en la CDN y en el CEDH. Así lo reclaman las más altas instancias europeas. En relación con los menores extranjeros no acompañados, el reto no es reconocer derechos, pues ya lo están, sino garantizarlos efectivamente.

\footnotetext{
42 Recomendación 1985 (2011) del Comité de Migración, Refugiados y Migración de la Asamblea Parlamentaria del Consejo de Europa, con el título "Menores migrantes indocumentados in situación irregular: un motivo real de preocupación".
} 


\section{Abstract}

\section{Detention of unaccompanied foreign minors in Europe:} the need to effectively ensure recognized rights

In several documents approved between 2010 and 2012, the Council of Europe and the European Union openly acknowledge that they have not taken sufficient measures to effectively guarantee the rights of unaccompanied foreign minors recognized by the United Nations Convention on the rights of the child in Europe (1989). Referring to the condition under which they can be detained, it urges the implementation of a common procedure capable of safeguarding the administrative and judicial protection of these minors.

Keywords: unaccompanied foreign minors in Europe, detention, inhuman or degrading treatment, interest of the child, European Court of Human Rights.

Recebido para publicación en 25/02/2014.

Aceptado para publicación en 20/05/2014.

Received for publication in February, 25 $5^{\text {th }}, 2014$.

Accepted for publication in May, $20^{\text {th }}, 2014$.

ISSN impresso: 1980-8585

ISSN eletrônico: 2237-9843 